\title{
Risk of spontaneous vertebral fracture during bisphosphonates drug holiday
}

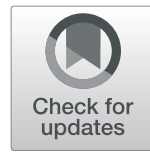

Ahmed Aboughanima ${ }^{1,2}$ (1)

\begin{abstract}
Background: Bisphosphonates are the most common treatment for osteoporosis with confirmed efficacy. However, less information is available on prolonged use. This study was performed to examine the risk of osteoporotic vertebral fractures during bisphosphonates holiday and estimate its predictors.

Results: Forty-two patients completed 2-year fracture-free holiday; 7 had spontaneous vertebral fracture. Among baseline characteristics, age was significantly higher in fracture group (69.99 \pm 3.62 vs. $75.37 \pm 3.81$; $P$ value 0.007); other factors were comparable. Longitudinal changes analysis showed that only alkaline phosphatase (ALP) increment had significant group over time interaction ( $P$ value 0.002). The difference between baseline and clinical end-point serum collagen type 1 cross-linked C-telopeptid (CTX) was significant in both fracture and non-fracture groups, whereas femoral neck and total hip BMD decline was significant in fracture group only. Multivariate analysis showed that only age $(O R, 1.43 ; p, 0.011)$ and history of previous fractures $(O R, 13.59 ; p, 0.044)$ are significant predictors of vertebral fractures.

Conclusions: These results suggest that older age and history of previous fracture should be considered as risk factors for vertebral fractures during bisphosphonates holiday. Furthermore, femoral neck and total hip BMD decline could be related to vertebral fractures. By the same token, overt increase of ALP and CTX could be an indicator of fracture occurrence.
\end{abstract}

Keywords: Osteoporosis, Alendronate, Drug holiday, Vertebral fracture

\section{Background}

Vertebral compression fractures are the most common osteoporotic fracture [1] which constitutes a main challenge in the elderly population. These fractures are associated with higher morbidity and mortality, in addition to the economic burden as a consequence of direct and indirect costs $[2,3]$.

Bisphosphonates are the prevalent treatment for osteoporosis. Its efficacy, when used for 3-5 years, in increasing bone mineral density (BMD) and reducing fracture risk in postmenopausal women has been confirmed [4]. However, there are growing recommendations of

Correspondence: dr_ahmedtaha73@yahoo.com

'Department of Rheumatology \& Rehabilitation, Faculty of Medicine, Benha University, Benha, Egypt

${ }^{2}$ Department of Internal Medicine, Rheumatology Division, Dallah Hospital, Riyadh, Kingdom of Saudi Arabia

\section{Springer Open}

utilizing bisphosphonates' drug holiday because of the inadequate data for prolonged use and the concerns regarding long-term safety. Rare yet still serious adverse events have been reported, which include osteonecrosis of the jaw, atypical femoral fractures, and increased risk of atrial fibrillation [5-8].

The ideal duration of the bisphosphonates' suspension and the risk factors for drug holiday-related vertebral fractures are not well-established yet. Previous studies have shown that BMD persist higher than baseline values after 5 years of alendronate holiday, even bone turnover remained partially suppressed, but the risk of clinical vertebral fractures was significantly increased $[9$, 10]. On the other hand, zoledronic acid discontinuation after 3 years resulted in increased monomorphic vertebral fractures compared to those who continued treatment for 6 years [11]. Nevertheless, there is no clear

(c) The Author(s). 2020 Open Access This article is licensed under a Creative Commons Attribution 4.0 International License, which permits use, sharing, adaptation, distribution and reproduction in any medium or format, as long as you give appropriate credit to the original author(s) and the source, provide a link to the Creative Commons licence, and indicate if changes were made. The images or other third party material in this article are included in the article's Creative Commons licence, unless indicated otherwise in a credit line to the material. If material is not included in the article's Creative Commons licence and your intended use is not permitted by statutory regulation or exceeds the permitted use, you will need to obtain permission directly from the copyright holder. To view a copy of this licence, visit http://creativecommons.org/licenses/by/4.0/. 
algorithm for choosing drug holiday candidate perfectly yet, coupled with the lack of trials to differentiate among the risk factors associated with various fracture sites [5]. The aim of this study was to describe the clinical, laboratory, and BMD changes during bisphosphonates 2 years drug holiday in postmenopausal women and to detect the predictors of spontaneous vertebral fractures during this holiday.

\section{Methods}

\section{Patients}

In the study, postmenopausal women who visited Rheumatology clinic, Dallah Hospital, Riyadh, Saudi Arabia, during the period from January 2016 to February 2017 were included. Eligible patients for enrollment were female patients with primary osteoporosis, who completed 5 years on alendronate or 3 years on zoledronic acid, with adherence rate to the medication more than $80 \%$; the adherence was assessed and documented as reported by the participants. Patients who had previous vertebral fractures or medical conditions resulting in secondary osteoporosis such as kidney failure, liver impairment, Cushing's disease, hyperthyroidism, hyperparathyroidism, hyperparathyroidism, hypocalcemia, rheumatoid arthritis, or Paget's disease of the bone were excluded. In addition to subjects taking corticosteroids, Proton Pump Inhibitors (PPIs), histamine2 receptor blockers, furosemide, statins, thiazolidinediones (TZDs), denosumab, teriparatide, and hormone replacement therapy, patients with high risk of fracture or high risk of fall, as defined by The Fracture Risk Assessment Tool (FRAX) and The Falls Risk Assessment Tool (FRAT) scores respectively, were excluded as well. The protocol of the study was approved by the hospital scientific and ethics committee, and all patients provided written consent.

\section{Study design and data collection}

This study was a single-center prospective study. Subjects on bisphosphonates treatment were prospectively identified by the investigators, and eligible patients who agreed to participate were enrolled. The decision to stop bisphosphonates was made after discussion with the subject about potential benefits and risks based on the available information. No data were collected for patients who refused to participate.

The date of the patient's initial visit for the current medical condition was designated as day 0 for follow-up. Each patient underwent medical history taking and full physical examination, in addition to antero-posterior and lateral spine X-ray to rule out old vertebral fractures. Characteristics were recorded, including age, body mass index (BMI), lumbar spine, total hip and femoral neck (FN) BMD and T scores, parathyroid hormone ( $\mathrm{PTH}$ ), vitamin D level, alkaline phosphatase (ALP) as bone formation indicator, serum collagen type 1 cross- linked C-telopeptid (CTX ) as bone resorption marker, risk of fall using FRAT-up score, and risk of fracture using FRAX score. FRAT-up score was calculated using the online tool (http://ffrat.farseeingresearch.eu), version 3.3, University of Bologna, 2016. High risk of fall was defined as FRAT-up score equal or more than 0.5. FRAX score, as well, was assessed using the online tool (https://www.sheffield.ac.uk/FRAX), version 4.1, University of Sheffield, UK. High probability of 10-year fracture was considered in patients with FRAX score of more than $3 \%$ for hip fracture or $20 \%$ for major osteoporotic fracture.

After day 0 , follow-up data on the patient's clinical status were recorded at $6,12,18$, and 24 months, as well as BMI, BMD assessments, and laboratory work-up. The primary outcome of the study was clinical or morphometric vertebral fracture. Data collection was ended when fracture of any type occurred or when the patient died or could no longer be followed. Patients with vertebral and non-vertebral traumatic fractures were not included in the study data final analysis.

During the study, any patient who reported clinical symptoms of fracture was diagnosed with appropriate radiographic imaging. Lumber spine radiograph was routinely done every visit and compared to the baseline images. The diagnosis of vertebral fracture was documented and coded according to the ICD-10-CM (M80.08).

\section{Statistical analysis}

Data analysis was performed using the SPSS version 24 (IBM Corp., Armonk, NY, USA) software. Continuous variables were reported as mean \pm standard deviation and dichotomous variables as number and proportion.

Student's $t$ test, Mann-Whitney $U$ test, chi-squared test, or Fisher's exact tests were conducted for data comparison as appropriate. All the potential predictors for vertebral fracture by previous analyses were subsequently enrolled into the univariate analysis. Consequently, variables with a $P$ value $<0.2$ by the univariate logistic analysis were entered to the multivariate analysis using binary logistic regression.

The change of measurements of BMI, ALP, CTX, femoral neck, total hip, and lumbar BMD during follow-up visits was verified using GLM repeated measures analysis of covariance. Two-sided $P$ values of less than 0.05 were considered to indicate statistical significance.

\section{Results}

\section{Characteristics of patients}

On February 20, 2017, recruitment was held; a total of 85 patients have met the eligibility criteria and followed up for 2 years. Last patient follow-up was completed on 20th of February 2019. During the follow-up period, 7 patients had vertebral fractures, 5 of them were 
morphometric fractures, 3 patients had non-vertebral fracture, 2 patients died, and 31 patients were lost contact. Final data analysis included 42 patients, completed 2-year drug holiday without fractures, and 7 patients who had vertebral fracture (Fig. 1).

The mean age $( \pm \mathrm{SD})$ of patients was $70.76 \pm 4.08$ years; age was significantly lower in non-fracture group (69.99 \pm 3.62 vs. $75.37 \pm 3.81$; $P$ value 0.007 ), while $B$ MI was almost the same. The frequency of diabetes, smoking, and history of previous fractures was numerically higher in patients who developed vertebral fractures, but no statistical significance was detected. Also, baseline FRAX risk of major fracture, FRAT score, ALP, PTH, and vitamin D was nonsignificantly higher in fracture group, whereas BMD measurements, CTX, and FRAX risk of hip fracture were numerically lower in fracture group of patients. Regarding bisphosphonates type, 3 patients were treated with zoledronic acid and 82 patients with alendronate. Overall, there was a correlation between older age, baseline lower (FN) BMD, and vertebral fracture (Fig. 2). Other demographic and clinical profiles were comparable without significant difference (Table 1).

\section{Follow-up measurements}

Comparison between fracture and non-fracture groups regarding longitudinal changes in ALP with the repeated measures ANCOVA revealed significant group over time interaction ( $P$ value 0.002$)$, while CTX increment was not significant.

No significant changes in body weight and vitamin $\mathrm{D}$ were noticed. Femoral neck and total hip BMD showed insignificant decline at the end of the study, whereas lumbar BMD remained almost at the same level (Table 2, Fig. 3).

\section{Primary end-point measurements difference}

Table 3 shows the difference between baseline and clinical end-point measurements, defined as completing 2year holiday or having spontaneous vertebral fracture, in addition to their confidence intervals. CTX difference

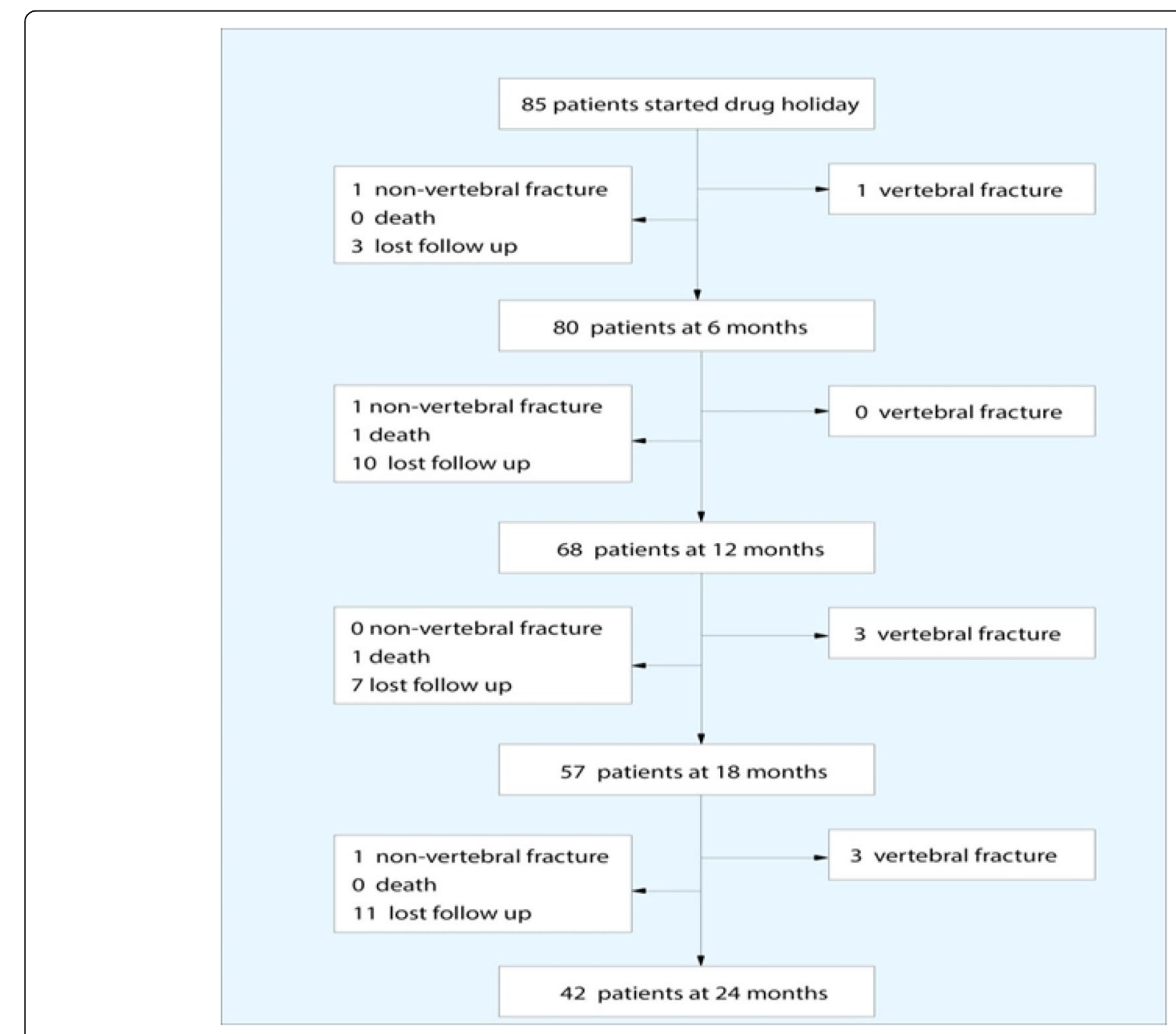

Fig. 1 Flowchart of the study 


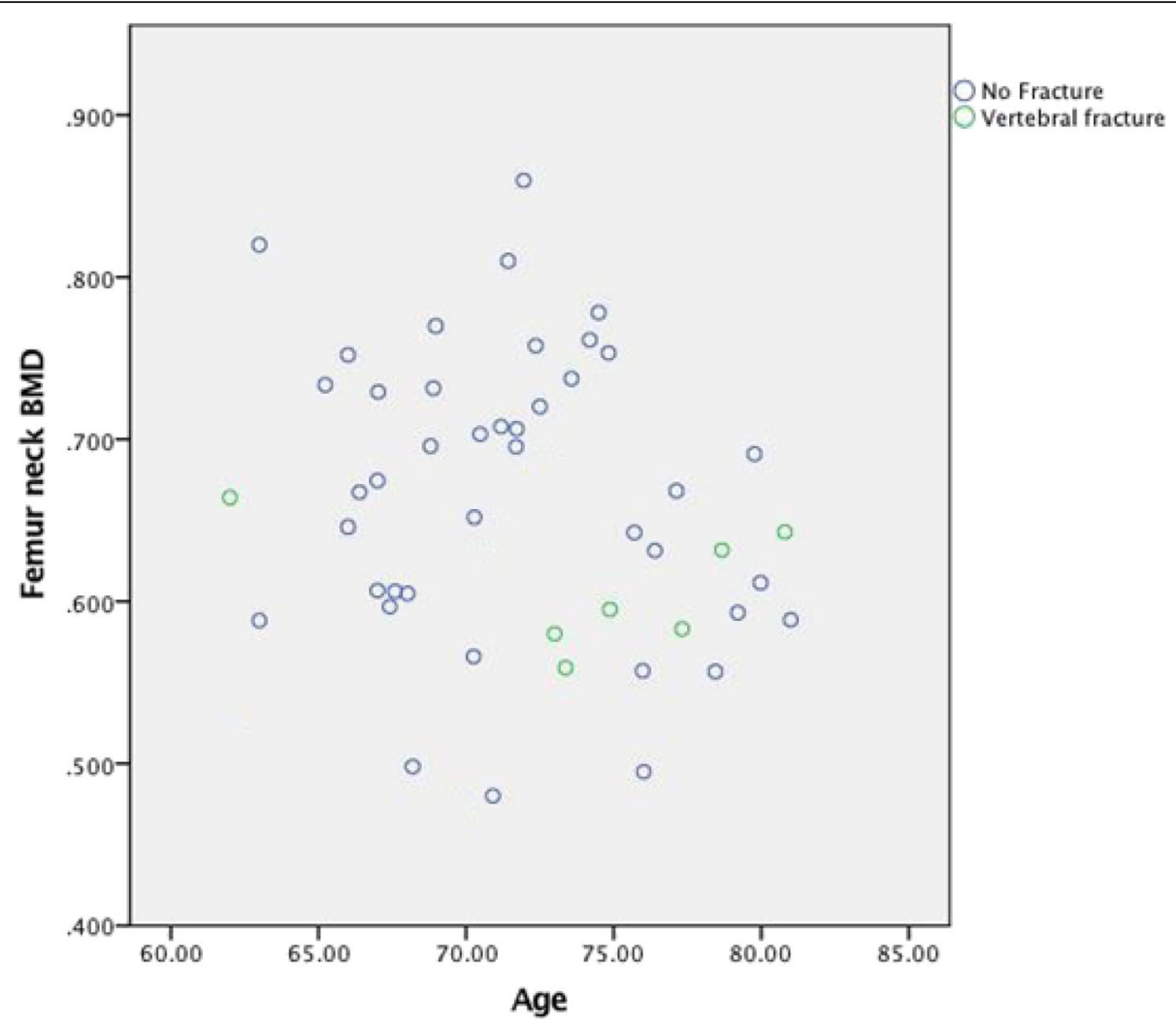

Fig. 2 Age to baseline femoral neck BMD relation

Table 1 Demographic and baseline clinical characteristics

\begin{tabular}{llll}
\hline & Total, $N=49$ & Completed holiday, $N=42(85.7 \%)$ & Vertebral fracture, $N=7(14.3 \%)$ \\
\hline Age & $70.76 \pm 4.08$ & $69.99 \pm 3.62$ & $75.37 \pm 3.81$ \\
BMI & $29.70 \pm 3.51$ & $29.62 \pm 3.57$ & $30.20 \pm 3.32$ \\
DM & $9(18.6 \%)$ & $7(16.7 \%)$ & $2(28.6 \%)$ \\
Smoker & $6(12.2 \%)$ & $5(11.9 \%)$ & $1(14.3 \%)$ \\
Previous fractures & $14(28.6 \%)$ & $10(23.8 \%)$ & $4(57.1 \%)$ \\
Zoledronic acid & $3(6.1 \%)$ & $2(4.8 \%)$ & $1(14.3 \%)$ \\
FRAT-up score & $0.205 \pm 0.032$ & $0.203 \pm 0.033$ & $0.215 \pm 0.027$ \\
FRAX_All & $11.53 \pm 2.64$ & $11.34 \pm 2.72$ & $12.71 \pm 1.79$ \\
FRAX_Hip & $1.35 \pm 0.53$ & $1.38 \pm 0.53$ & $1.21 \pm 0.52$ \\
FN BMD & $0.660 \pm 0.090$ & $0.668 \pm 0.094$ & $0.607 \pm 0.038$ \\
Lumbar BMD & $0.894 \pm 0.134$ & $0.901 \pm 0.143$ & $0.850 \pm 0.043$ \\
Hip BMD & $0.803 \pm 0.115$ & $0.806 \pm 0.120$ & $0.787 \pm 0.089$ \\
FN T score & $-1.79 \pm 0.46$ & $-1.75 \pm 0.47$ & $-2.02 \pm 0.29$ \\
Lumbar T score & $-1.68 \pm 0.42$ & $-1.69 \pm 0.43$ & $-1.66 \pm 0.39$ \\
Hip T score & $-1.60 \pm 0.48$ & $-1.59 \pm 0.50$ & $-1.67 \pm 0.38$ \\
PTH & $48.52 \pm 17.55$ & $46.69 \pm 17.88$ & $49.51 \pm 10.64$ \\
Vitamin D & $60.12 \pm 19.21$ & $59.25 \pm 17.49$ & $65.31 \pm 28.70$ \\
ALP & $52.67 \pm 10.20$ & $52.03 \pm 10.44$ & $56.48 \pm 8.24$ \\
CTX & $0.196 \pm 0.082$ & $0.197 \pm 0.036$ & $0.191 \pm 0.088$
\end{tabular}


Table 2 Follow-up measurements during drug holiday

\begin{tabular}{|c|c|c|c|c|c|c|}
\hline & & 6 months & 12 & 18 & 24 & $P$ value \\
\hline \multirow[t]{2}{*}{ BMI } & Fracture & $30.13 \pm 2.02$ & $30.11 \pm 3.71$ & $30.63 \pm 3.28$ & $30.45 \pm 1.3$ & 0.442 \\
\hline & No fracture & $29.61 \pm 2.40$ & $29.81 \pm 2.80$ & $29.70 \pm 3.27$ & $29.74 \pm 2.6$ & \\
\hline \multirow[t]{2}{*}{ ALP } & Fracture & $57.60 \pm 7.86$ & $61.59 \pm 5.25$ & $63.07 \pm 4.50$ & $66.32 \pm 5.03$ & $0.002^{*}$ \\
\hline & No fracture & $54.79 \pm 12.75$ & $53.48 \pm 13.80$ & $54.73 \pm 10.41$ & $57.08 \pm 13.80$ & \\
\hline \multirow[t]{2}{*}{ CTX } & Fracture & $0.210 \pm 0.035$ & $0.280 \pm 0.036$ & $0.309 \pm 0.026$ & $0.324 \pm 0.030$ & 0.572 \\
\hline & No fracture & $0.215 \pm 0.073$ & $0.253 \pm 0.086$ & $0.286 \pm 0.081$ & $0.299 \pm 0.081$ & \\
\hline \multirow[t]{2}{*}{ Vitamin D } & fracture & $65.22 \pm 28.08$ & $67.59 \pm 22.04$ & $67.76 \pm 27.46$ & $67.30 \pm 27.77$ & 0.385 \\
\hline & No fracture & $59.54 \pm 17.00$ & $59.49 \pm 16.29$ & $58.17 \pm 16.30$ & $59.14 \pm 19.60$ & \\
\hline \multirow[t]{2}{*}{ FN BMD } & Fracture & $0.605 \pm 0.038$ & $0.596 \pm 0.038$ & $0.592 \pm 0.039$ & $0.572 \pm 0.032$ & 0.056 \\
\hline & No fracture & $0.670 \pm 0.100$ & $0.658 \pm 0.108$ & $0.662 \pm 0.088$ & $0.655 \pm 0.091$ & \\
\hline \multirow[t]{2}{*}{ Lumbar BMD } & Fracture & $0.883 \pm 0.081$ & $0.849 \pm 0.070$ & $0.875 \pm 0.076$ & $0.839 \pm 0.103$ & 0.259 \\
\hline & No fracture & $0.886 \pm 0.121$ & $0.878 \pm 0.089$ & $0.880 \pm 0.118$ & $0.880 \pm 0.115$ & \\
\hline \multirow[t]{2}{*}{ Hip BMD } & Fracture & $0.762 \pm 0.056$ & $0.747 \pm 0.144$ & $0.671 \pm 0.108$ & $0.647 \pm 0.106$ & 0.352 \\
\hline & No fracture & $0.797 \pm 0.158$ & $0.786 \pm 0.185$ & $0.739 \pm 0.216$ & $0.707 \pm 0.198$ & \\
\hline
\end{tabular}

$B M I$ body mass index, ALP alkaline phosphatase, CTX serum collagen type 1 cross-linked C-telopeptid, FN BMD femoral neck bone mineral *Significant

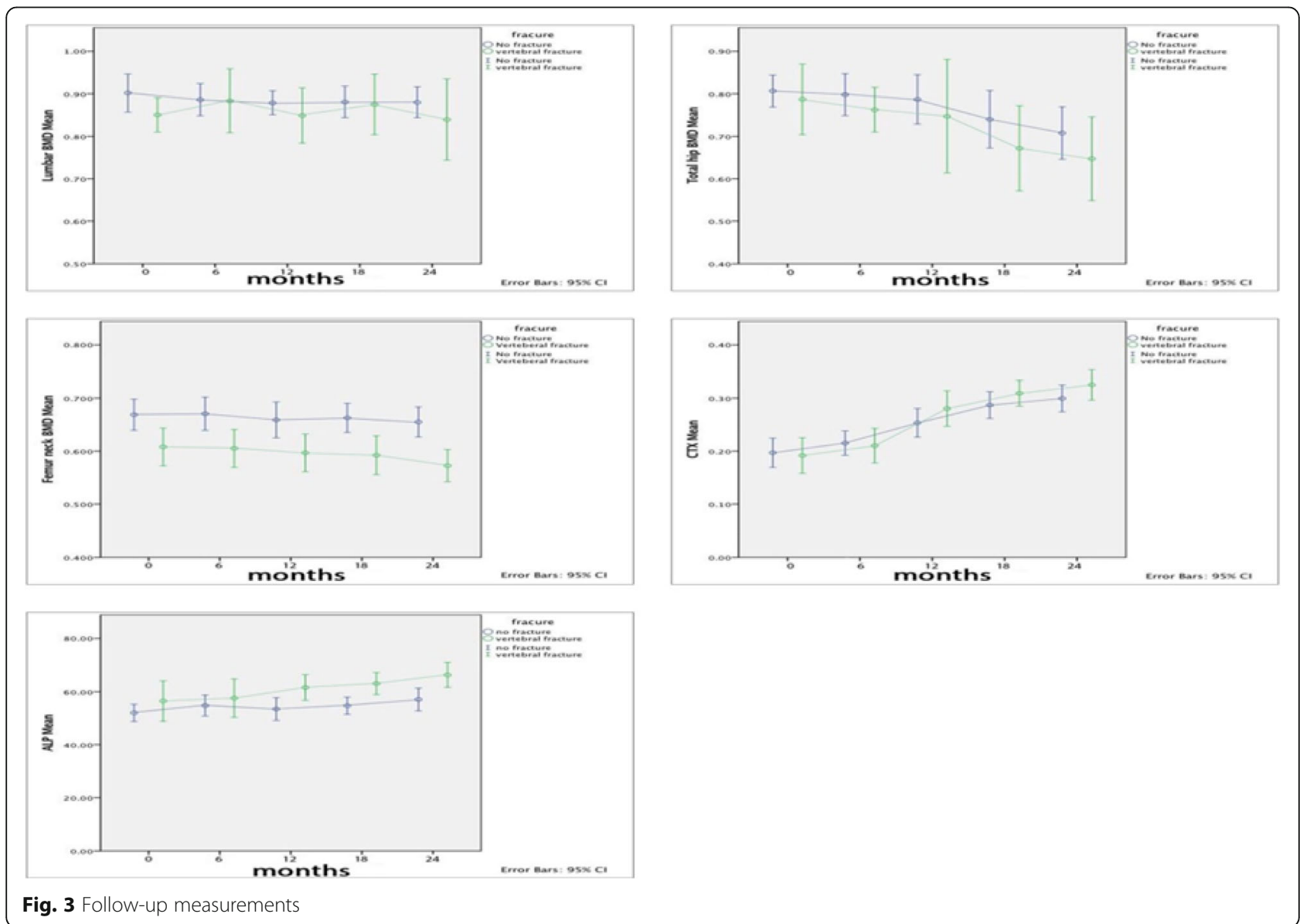

Fig. 3 Follow-up measurements 
Table 3 The measurements difference at the end-point

\begin{tabular}{llll}
\hline & & Mean difference $(95 \% \mathrm{Cl})$ & $P$ value \\
\hline FN BMD & Fracture & $-0.036(-0.044$ to -0.012$)$ & $0.041^{*}$ \\
& No fracture & $-0.013(-0.026$ to 0.006$)$ & 0.228 \\
Lumbar BMD & Fracture & $-0.011(-0.042$ to 0.032$)$ & 0.445 \\
& No fracture & $-0.023(-0.032$ to 0.052$)$ & 0.364 \\
Total hip BMD & Fracture & $-0.132(-0.199$ to -0.080$)$ & 0.001 \\
& No fracture & $-0.099(-0.044$ to 0.083$)$ & 0.539 \\
CTX & Fracture & $0.133(0.082$ to 0.096$)$ & $<0.001^{*}$ \\
& No fracture & $0.102(0.030$ to -0.082$)$ & $<0.001^{*}$ \\
ALP & Fracture & $9.84(-1.232$ to 15.634$)$ & 0.067 \\
& No fracture & $5.056(-1.332$ to 9.321$)$ & 0.568
\end{tabular}

$B M D$ bone mineral density, FN BMD femoral neck bone mineral density, $A L P$ alkaline phosphatase, CTX serum collagen type 1 cross-linked C-telopeptid *Significant

after the drug holiday was significant in both groups. Femoral neck and total hip BMD decline were significant as well in fracture group only. On the other hand, ALP, lumbar BMD difference was not significant.

\section{Determining the independent predictors of vertebral fracture}

Multivariate analysis using stepwise binary logistic progression showed that only age $(\mathrm{OR}, 1.43 ; P, 0.011)$ and history of previous fractures (OR, 13.59; $P, 0.044)$ are significant predictors of vertebral fractures. Conversely, the change in patients' BMI, total hip and FN-BMD, ALP, and CTX change did not seem to affect vertebral fractures prediction model (Table 4).

\section{Discussion}

Osteoporosis is a considerable health problem; furthermore, it was assessed that $40 \%$ postmenopausal women and $30 \%$ men will encounter an osteoporotic fracture in the remainder of their lives [12]. Markedly, osteopenia and osteoporosis incidence rises with age, and their complications including fracture, disability, mortality,

Table 4 Multivariate analysis of vertebral fracture

\begin{tabular}{llllll}
\hline & $B$ & $\begin{array}{l}P \\
\text { value }\end{array}$ & OR & & $95 \% \mathrm{Cl}$ \\
\cline { 5 - 6 } & & & & Lower & Upper \\
\hline Age & 0.358 & $0.011^{*}$ & 1.43 & 1.087 & 1.881 \\
BMI & 0.159 & 0.339 & 1.17 & 0.846 & 1.625 \\
Previous fracture & 2.610 & $0.044^{*}$ & 13.59 & 1.072 & 172.373 \\
FN BMD change & 1.018 & 0.673 & 2.10 & 0.004 & 14.507 \\
Total hip BMD change & 1.021 & 0.546 & 1.82 & 0.032 & 12.43 \\
CTX change & 0.850 & 0.388 & 1.92 & 0.001 & 9.811 \\
ALP change & 0.065 & 0.193 & 1.06 & 0.968 & 1.177 \\
\hline BMI body mass
\end{tabular}

$B M I$ body mass index, FN BMD femoral neck bone mineral density, ALP alkaline phosphatase, CTX serum collagen type 1 cross-linked C-telopeptid *Significant and economic costs increase as well $[13,14]$. It has been reported that a previous fracture is a noteworthy hazard for a subsequent fracture. Patients with history of sustained fragility fracture have $86 \%$ higher incidence for any consequent fracture [15]. The occurrence of vertebral fracture increments with age in both genders [16], additionally a $10 \%$ reduction in the spinal and/or hip bone mass, results in 2- and 2.5-fold increase risk of developing vertebral and/or hip fractures, respectively [17].

Even though rates of morphometric vertebral fractures were comparable among patients who continued alendronate and those who discontinued it in FLEX $\operatorname{trial}(11.3 \%$ vs $9.8 \%)$, the risk of clinical vertebral fracture was significantly lower (5.3\% vs $2.4 \%$; RR, $0.45 ; 95 \% \mathrm{CI}$ 0.24-0.85) among patients who continued alendronate $[9,10]$, but subgroup analysis showed that vertebral fractures were reduced significantly in women with femur neck $\mathrm{T}$ score -2.5 to -2.0 group only; conversely, there was no difference in other groups $[10,18]$. Correspondingly, there was significant reduction in morphometric vertebral fracture in participants with low femoral or total hip $\mathrm{T}$ score who continued zoledronic acid for 6 years compared to 3 years group $(\mathrm{OR}=0.51 ; 95 \% \mathrm{CI}$ $0.26-0.95)[11,19,20]$.

Bisphosphonates are the most common used medications for treatment of osteoporosis [21, 22]; they show potent efficacy in reducing osteoporotic vertebral fractures with relative risk reduction 0.53 for morphometric vertebral fractures $(95 \% \mathrm{Cl} 0.41-0.68)$ and 0.45 for clinical vertebral fractures $(0.27-0.72)[9,23]$. However, long-term bisphosphonates use has been connected to rare but serious adverse events including esophageal cancer, esophagitis, gastritis, osteonecrosis of the jaw, atypical femoral fractures, and increased risk of atrial fibrillation. Additionally, FLEX and HORIZON trials did show increased overall non-vertebral fracture risk in alendronate vs. placebo after 5 years and zoledronic acid vs. placebo after 3 years, respectively. Consequently, physicians are increasingly considering discontinuation of bisphosphonates more [18, 24-26]. The American Association of Endocrinologists/American College of Endocrinology 2016 Postmenopausal Osteoporosis Treatment Algorithm stated that bisphosphonate drug holiday could be considered after 5 years of oral and 3 years of IV therapy, and treatment should be resumed when a new fracture occurs, BMD declines beyond least significant change (LSC), bone-turnover markers (BTMs) rise to pretreatment values, or patient meets initial treatment criteria [27]. On the other hand, extension trials of FLEX and HORIZON demonstrated increment in vertebral fractures [23].

In this study, 85 postmenopausal women were prospectively followed to examine the risk factors related to the osteoporotic vertebral fractures that happen after 
discontinuation of bisphosphonates for 2 years. Seven patients developed spontaneous vertebral fracture, while the majority of the patients were able to complete the drug holiday without any fractures $(N=42)$, which can be explained by the long half-life of bisphosphonates medication class and their sustained effect on bone turnover and reabsorption. The rate of vertebral fractures is close to the rate reported in previous studies.

There were recommendations to monitor BMD and BTMs yearly after discontinuation of bisphosphonate $[23,28]$, but post hoc testing of FLEX trial found that neither hip BMD nor BTMs change after 1 and 3 years are significant predictors of fracture risk [24]. In this study, the comparison between participants who developed vertebral fracture and those who completed 2-year holiday did not demonstrate any significant difference in the baseline CTX, ALP, total hip, FN, and femur T score. In contrast, previous post hoc analysis reported low hip BMD, at bisphosphonate discontinuation time, as strong predictor of fracture [28]. Our data showed non-significant lower baseline hip BMD, but significant difference of hip BMD at the end of the study in fracture group, it could be due to the limited incidence of fractures. Further trials are needed to confirm the relationship between baseline hip BMD and vertebral fractures.

Measurements of difference after the holiday showed numerical drop of the BMD values for both groups, but only the change in femur neck and total hip BMD of fracture group after the holiday was significant. Conversely, ALP and CTX values increased during the drug suspension, but only CTX difference was significant in both fracture and non-fracture groups. Given these points, rapid femur neck and hip BMD loss and CTX increment after the discontinuation of bisphosphonates could be an indicator for vertebral fracture risk.

The analysis of repeated measurements between groups (fracture vs. non-fracture) over time (day 0 to 2 years or end-point) demonstrated significant interaction difference for ALP only; this difference over time between the two groups could be due to the fracture occurrence, which increased ALP in the fracture group. On the contrary, no significant difference over time was found in CTX, BMD, BMI, and vitamin D. During the follow-up period of the study, all patients received educational instructions regarding diet and physical activity, and vitamin $\mathrm{D}$ was maintained at normal levels throughout the study with monthly supplementation of 50,000 $\mathrm{IU}$ and $600 \mathrm{mg}$ of elemental calcium at least.

Many studies have identified older age as risk factor for fracture $[1,10,11,16]$; similarly, this study revealed that older age increased the probability of vertebral fracture; nevertheless, larger-scale trial is needed to explore the disparities between various age groups and potentially determine cut-off age for patients who get benefit from bisphosphonates drug holiday. The other significant predictor in our multifactorial analysis was history of previous fractures. Multivariate stepwise logistic regression model showed that patients who have had fractures earlier are at risk, almost 14 folds, to develop new vertebral fractures. Those patients could be possibly considered for continuing of bisphosphonates after 5 years or to be shifted to other treatments.

This study has the strengths of being prospective in design, focusing on vertebral fractures. All patients were followed every 6 months with BTMs, X-rays, and DXA scans. However, the outcome of this study has to be approached in the light of its limitations. Firstly, our study was a single-center study; for this reason, the sample size was small with a few cases of end-point incidence (vertebral fracture); as a result, we have not been able to do survival analysis of the duration of time to fracture and its associated risk factors. Secondly, we excluded patients with secondary osteoporosis, so our conclusions cannot be generalized to all postmenopausal osteoporotic women.

\section{Conclusion}

This study showed that the incidence of spontaneous vertebral fracture among postmenopausal women without secondary causes during 2-year drug holiday is about $17 \%$. Risk factors of developing those fractures include older age and history of having previous fracture. Furthermore, femoral neck and total hip BMD decline could be related to vertebral fractures. By the same token, overt increase of ALP and CTX could be an indicator of fracture occurrence. Other trials are needed to create stable model of predictors regarding candidate patients for drug holiday in terms of age, BTMs, and BMD rate of change and the risk of developing vertebral fractures.

\section{Abbreviations}

BMD: Bone mineral density; ALP: Alkaline phosphatase; CTX: Collagen type 1 cross-linked C-telopeptid; PPIs: Proton Pump Inhibitors;

TZDs: Thiazolidinediones; FRAX: The Fracture Risk Assessment Tool; FRAT: The Falls Risk Assessment Tool; BMl: Body mass index; FN: Femoral neck;

PTH: Parathyroid hormone; SD: Standard Deviation; LSC: Least significant change; BTM: Bone-turnover markers; DM: Diabetes mellitus

\section{Acknowledgements}

Not applicable.

\section{Author's contributions}

The author collected patients, analyzed and interpreted the patients' data, performed full history taking and full clinical examination, revised statistical analysis, and was the only contributor in writing the manuscript. The author read and approved the final manuscript.

\section{Funding}

None

Availability of data and materials

The data sets used and/or analyzed during the current study are available from the corresponding author on responsible request 


\section{Ethics approval and consent to participate}

The protocol of the study was approved by the hospital scientific and ethics committee (Dalh hospital scientific and ethics committee); the reference number is not applicable, and all patients provided written consent.

\section{Consent for publication}

Not applicable.

\section{Competing interests}

The author declares that he has no competing interests.

Received: 1 May 2020 Accepted: 26 June 2020

Published online: 16 November 2020

\section{References}

1. Waterloo S, Ahmed LA, Center JR, Eisman JA, Morseth B, Nguyen ND et al (2012) Prevalence of vertebral fractures in women and men in the population-based Tromsø study. BMC Musculoskelet Disord 17(13):3. https:// doi.org/10.1186/1471-2474-13-3

2. Blume SW, Curtis JR (2011) Medical costs of osteoporosis in the elderly Medicare population. Osteoporos Int 22:1835-1844

3. Hasserius R, Karlsson MK, Jónsson B, Redlund-Johnell I, Johnell O (2005) Long-term morbidity and mortality after a clinically diagnosed vertebral fracture in the elderly--a 12- and 22-year follow-up of 257 patients. Calcif Tissue Int 76:235-242

4. Tonino RP, Meunier PJ, Emkey R, Rodriguez-Portales JA, Menkes CJ, Wasnich $R D$, et al. Skeletal benefits of alendronate: 7-year treatment of postmenopausal osteoporotic women. Phase III Osteoporosis Treatment Study Group. J Clin Endocrinol Metab 2000; 85:3109-3115

5. Adler RA, El-Hajj Fuleihan G, Bauer DC, Rodriguez-Portales JA, Menkes CJ, Wasnich RD et al (2016) Managing osteoporosis in patients on long-term bisphosphonate treatment: report of a task force of the American Society for Bone and Mineral Research. J Bone Miner Res 31:16-35

6. Cosman F, de Beur SJ, LeBoff MS, Lewiecki EM, Tanner B, Randall S, Lindsay R (2014) Clinician's guide to prevention and treatment of osteoporosis. Osteoporos Int 25:2359-238

7. Loke YK, Jeevanantham V S Singh S (2009) Bisphosphonates and atrial fibrillation: systematic review and meta-analysis. Drug Saf 32:219-228

8. Sharma A, Chatterjee S, Arbab-Zadeh A (2013) Risk of serious atrial fibrillation and stroke with use of bisphosphonates: evidence from a metaanalysis. Chest. 144:1311-1322

9. Black DM, Schwartz AV, Ensrud KE, Cauley JA, Levis S, Quandt SA, et al. Effects of continuing or stopping alendronate after 5 years of treatment: the Fracture Intervention Trial Long-term Extension (FLEX): a randomized trial. JAMA. 2006;296:2927-2938

10. Schwartz AV, Bauer DC, Cummings SR, Cauley JA, Ensrud KE, Palermo L et al (2010) Efficacy of continued alendronate for fractures in women with and without prevalent vertebral fracture: the FLEX trial. J Bone Miner Res 25: 976-982

11. Black DM, Reid IR, Cauley JA, Cosman F, Leung PC, Lakatos $P$, et al. The effect of 6 versus 9 years of zoledronic acid treatment in osteoporosis: a randomized second extension to the HORIZON-Pivotal Fracture Trial (PFT). J Bone Miner Res 2015; 30:934-944

12. Wright NC, Looker AC, Saag KG, Curtis JR, Delzell ES, Randall S et al (2014) The recent prevalence of osteoporosis and low bone mass in the United States based on bone mineral density at the femoral neck or lumbar spine. J Bone Miner Res 29:2520-2526

13. Hasserius R, Karlsson M., Nilsson B, , Johnell O,. Prevalent vertebral deformities predict increased mortality and increased fracture rate in both men and women: a 10-year population-based study of 598 individuals from the Swedish cohort in the European Vertebral Osteoporosis Study. Osteoporos Int 2003; 14: 61-68 https://doi.org/10.1007/s00198-002-1316-9

14. Burge R, Dawson-Hughes B, Solomon DH, Wong JB, King A, Tosteson A (2007) Incidence and economic burden of osteoporosis-related fractures in the United States, 2005-2025. J Bone Miner Res 22:465-475

15. Kanis JA, Johnell O, De Laet $\mathrm{C}$, Johansson H, Oden A, Delmas PD et al (2004) A meta-analysis of previous fracture and subsequent fracture risk. Bone. 35(2):375-382

16. Davies KM, Stegman MR, Heaney RP, Recker RR (1996) Prevalence and severity of vertebral fracture: the Saunders County Bone Quality Study. Osteoporos Int 6:160-165
17. Klotzbuecher CM, Ross PD, Landsman PB, Abbott TA 3rd, Berger M (2000) Patients with prior fractures have an increased risk of future fractures: a summary of the literature and statistical synthesis. J Bone Miner Res 15:721-739

18. Ro C, Cooper O (2013) Bisphosphonate drug holiday: choosing appropriate candidates. Curr Osteoporos Rep 11(1):45-51. https://doi.org/10.1007/ s11914-012-0129-9

19. Black DM, Reid IR, Boonen S, Bucci-Rechtweg C, Cauley JA, Cosman F et al (2012) The effect of 3 versus 6 years of zoledronic acid treatment of osteoporosis: a randomized extension to the HORIZON-Pivotal Fracture Trial (PFT). J Bone Miner Res 27:243-254

20. Cosman F, Cauley J, Eastell R, Boonen S, Palermo L, Reid I et al (2014) Reassessment of fracture risk in women after 3 years of treatment with zoledronic acid: when is it reasonable to discontinue treatment? J Clin Endocrinol Metab 99:4546-4554

21. Bone $\mathrm{H}$, Hosking D, Devogelaer J, Tucci JR, Emkey RD, Tonino RP et al (2004) Ten years' experience with alendronate for osteoporosis in postmenopausal women. N Engl J Med 350:1189-1199

22. Favus MJ (2010) Bisphosphonates for osteoporosis. N Engl J Med 363(21): 2027-2035

23. Mignot MA, Taisne N, Legroux I, Cortet B, Paccou J (2017) Bisphosphonate drug holidays in postmenopausal osteoporosis: effect on clinical fracture risk. Osteoporos Int 28:3431-3438

24. Nayak S, Greenspan SL (2019) A systematic review and meta-analysis of the effect of bisphosphonate drug holidays on bone mineral density and osteoporotic fracture risk. Osteoporos Int 30(4):705-720 https://doi.org/10. 1007/s00198-018-4791-3

25. Watts NB, Diab DL (2010) Long-term use of bisphosphonates in osteoporosis. J Clin Endocrinol Metab 95(4):1555-1565

26. Boonen S, Ferrari S, Miller PD, Eriksen EF, Sambrook PN, Compston J et al (2012) Postmenopausal osteoporosis treatment with antiresorptives: effects of discontinuation or long-term continuation on bone turnover and fracture risk-a perspective. J Bone Miner Res 27(5):963-974

27. Camacho PM, Petak SM, Binkley N, Clarke BL, Harris ST, Hurley DL, et al. American Association of Clinical Endocrinologists and American College of Endocrinology clinical practice guidelines for the diagnosis and treatment of postmenopausal osteoporosis - 2016. Endocr Pract. 2016; Sep 2;22(Suppl 4):1-42. doi: https://doi.org/10.4158/EP161435.GL.

28. Bauer DC, Schwartz A, Palermo L, Cauley J, Hochberg M, Santora A et al (2014) Fracture prediction after discontinuation of 4 to 5 years of alendronate therapy: the FLEX study. JAMA Intern Med 174:1126-1134

\section{Publisher's Note}

Springer Nature remains neutral with regard to jurisdictional claims in published maps and institutional affiliations.

\section{Submit your manuscript to a SpringerOpen ${ }^{\circ}$ journal and benefit from:}

- Convenient online submission

- Rigorous peer review

- Open access: articles freely available online

- High visibility within the field

- Retaining the copyright to your article

Submit your next manuscript at $>$ springeropen.com 